\title{
Yıldız-Şekilli Poli(L-Laktik Asit) Nanokompozitlerin Yerinde Polimerizasyon Yöntemiyle Hazırlanması ve İncelenmesi
}

\author{
Naile Karakehya ${ }^{1 *}$, Ceyda Bilgiç² (D) \\ ${ }^{1}$ Eskişehir Osmangazi Üniversitesi, Eskişehir Meslek Yüksekokulu, Çevre Koruma Teknolojileri Bölümü, \\ Eskişehir \\ ${ }^{2}$ Eskişehir Osmangazi Üniversitesi, Mühendislik Mimarlık Fakültesi, Kimya Mühendisliği Bölümü, Eskişehir
}

Geliş / Received: 05/03/2020, Kabul / Accepted: 25/08/2020

\begin{abstract}
$\ddot{\mathbf{O} z}$
Poli(L-laktik asit) (PLLA) bir diğer adıyla poli(L-laktit), yenilenebilir kaynaklardan üretilen biyobozunur termoplastik bir polimerdir. $\mathrm{Bu}$ çalışmada çeşitli nano-dolgu maddeleri kullanılarak in-situ (yerinde) polimerizasyon yöntemi ile üç farklı PLLA nanokompozit hazırlanmıştır. Poli(L-laktik asit), L-laktit halka açılma polimerizasyonu ile elde edilmiştir. Başlatıcı olarak pentaeritritol, katalizör olarak kalay-2etilheksanoat $\left(\mathrm{Sn}(\mathrm{Oct})_{2}\right)$ kullanılarak yıldız-şekilli PLLA sentezlenmiştir. Dolgu maddeleri sisteme katalizör ekleme aşamasında katılmıştır. Kullanılan nano-seviyedeki dolgu maddeleri nanokristalin selüloz (NCC), organo-montmorillonit (OMMT) ve çok duvarlı karbon nanotüptür (CNT). Ağırlıkça \%2 dolgu maddesi içeren nanokompozitlerin 1sıl özellikleri termogravimetrik analiz (TGA) ile incelenmiştir. Yüzde 5 ve yüzde 50 ağırlık kaybı, maksimum ağırlık kaybı sıcaklıkları ve $500{ }^{\circ} \mathrm{C}$ 'deki çar miktarı belirlenmiştir. Hazırlanan nanokompozitlerin yüzey görüntüsü ve kristal yapısı taramalı elektron mikroskobu (SEM) ve X-1şını kırınım (XRD) yöntemiyle incelenmiştir. Bu çalışmada elde edilen saf PLLA'in 1sıl bozunma sıcaklık aralığg $250-300$ ${ }^{\circ} \mathrm{C}$ 'dir ve bozunma iki adımda gerçekleşmektedir. Saf PLLA ve PLLA nanokompozitler $220{ }^{\circ} \mathrm{C}$ 'ye kadar 1 sıl kararlılıklarını korumaktadırlar.
\end{abstract}

Anahtar Kelimeler: poli(laktik asit), yerinde polimerizasyon, nanokompozit, XRD, TGA

\section{Characterization Star-Shaped Poly(L-Lactic Acid) Nanocomposites Prepared by In-Situ Polymerization Method}

\begin{abstract}
Poly(L-lactic acid) (PLLA) also known as poly(L-lactide) is a biodegradable thermoplastic polymer produced from renewable sources. In this study, three different PLLA nanocomposites were prepared by in-situ polymerization method using various nano-fillers. Poly (L-lactic acid) was obtained by L-lactide ring opening polymerization. Star-shaped PLLA synthesized using pentaerythritol as the initiator and tin-2-ethylhexanoate $\left(\mathrm{Sn}(\mathrm{Oct})_{2}\right)$ as the catalyst. Fillers were added to the system during the catalyst addition step. The nano-level fillers used are nanocrystalline cellulose (NCC), organo-montmorillonite (OMMT) and multi-walled carbon nanotube (CNT). Thermal properties of nanocomposites containing $2 \%$ (by weight $\%$ ) filler were investigated by thermogravimetric analysis (TGA). The 5\% and 50\% weight loss, maximum weight loss temperatures and char amount at $500{ }^{\circ} \mathrm{C}$ were determined. Surface images and the crystallinity of the prepared nanocomposites were investigated by scanning electron microscopy (SEM) and X-ray diffraction (XRD) method. The thermal decomposition temperature range of pure PLLA obtained in this study is $250-300{ }^{\circ} \mathrm{C}$ and degradation takes place in two steps. Pure PLLA and PLLA nanocomposites maintain their thermal stability up to $220^{\circ} \mathrm{C}$.
\end{abstract}

Keywords: poly(lactic acid), in-situ polimerization, nanocomposites, XRD, TGA 


\section{Giriş}

Yenilenebilir kaynaklardan elde edilen polimerler (PLA ve selüloz gibi), biyomedikalden savunma sanayisine kadar birçok değişik alanda kullanılmaktadır (Thakur and Thakur, 2014). Poli(laktik asit), doğal (tarımsal) kaynaklardan üretilebilen, eriyik olarak harmanlanabilen ve enjeksiyonla kalıplanabilen hidrofobik bir polimerdir. Petrol bazlı polimerlere karşı çevre dostu bir alternatif olabilir. Geleneksel olarak polimerik maddelere, nihai ürünün özelliklerini geliştirmek veya maliyeti düşürmek için sentetik veya doğal dolgu maddeleri katılır. Ancak bu dolguların eklenmesinin elde edilen malzeme üzerinde ağırlık artışı, matlık, 1sıl ve mekanik özelliklerde kötüleşme gibi bazı istenmeyen etkilerinin olduğu bilinmektedir (Pavlidou and Papaspyrides, 2008). Bu da daha zayif malzemelerin elde edilmesine neden olmaktadır (Pan et al., 2004). Diğer taraftan yeni bir kompozit sinıfi olan nanokompozitlerde, dağılmış taneciklerinin en az bir boyutu nanometre seviyesindedir ve polimere ağırlıkça \%5 veya çok daha az miktarlarda katılırlar (Alexandre and Dubois, 2000). Böylece dolgu maddesi eklenmesiyle polimerin özelliklerinde oluşan olumsuzlukların önüne geçilmiş olur.

PLA, birçok kaynaktan üretilebilen, toksik olmayan biyo-uyumlu bir polimerdir. PLA günümüzde cerrahi dikişler, ilaç taşıyıcı sistemler, implantlar, yara örtüsü ve doku mühendisliği gibi birçok tıbbi uygulamada kullanılmaktadır (Lee et al., 2001). PLA sentezi, laktik asit monomerinin işlenmesini ve polimerizasyonunu içerir. Genellikle kondenzasyon polimerizasyonu veya halka açılması polimerizasyonu tercih edilir. Laktik asit kiral bir molekül olduğundan, PLA'nın poli(L-laktit) (PLLA), poli(D-laktit) (PDLA) ve poli(DL-laktit) (PDLLA) gibi stereoizomerleri vardir (Lopes et al., 2014). Bazı biyomedikal uygulamalarda ve gida ambalajlarında biyobozunur malzemenin kısa sürede bozunması istenebilir. Lineer yapıdaki PLA'nın bozunma süresi biraz uzundur, hatta bazı koşullarda birkaç yılı bulabilir. $\mathrm{Bu}$ nedenle bozunma süresini kısaltmak için yapılan işlemlerden biri yıldız-şekilli PLLA sentezidir (Teng et al., 2015). Kim ve arkadaşları, L-laktitin, pentaeritritol varlığında kalay oktoat $\left(\mathrm{Sn}(\mathrm{Oct})_{2}\right)$ katalizörü ile halka açılması polimerizasyonunda yüksek molekül ağırlıklı yıldız-şekilli (dört kollu) PLLA elde etmiştir. Yıldız-şekilli bir PLLA'nın üç veya daha fazla lineer kolu vardır ve lineer PLA'ya göre daha düşük bir kristaliniteye sahiptir (Kim et al., 1993). Günümüzde çok-kollu PLA üretiminde en çok kullanılan yöntem polimerizasyonda multifonksiyonel başlatıcılar kullanmaktır. Çok-kollu PLA sentezinde başarısı en yüksek kombinasyon ise multifonksiyonel hidroksil bileşikleri ile birlikte kalay-2-etilheksanoat kullanımidır (Finne and Albertsson, 2002). Dolayısıyla bu çalışmada da aynı kombinasyon tercih edilmiştir.

Günümüzde, polimer nanokompozitlerin hazırlanmasında yaygın olarak üç metot kullanılmaktadır. Bunlar, yerinde (in situ) polimerizasyon yöntemi, çözeltilerin birleştirilmesi yöntemi ve eriyik harmanlama yöntemidir. Yerinde polimerleşme, polimerkil nanokompozit sentezlemede kullanılan ilk metottur.

$\mathrm{Bu}$ çalışmanın amacı, çeşitli nano-dolgu maddelerinin PLLA nanokompozitlerin 1s1l özellikleri üzerindeki etkisini incelemektir. Daha ekonomik ve çevre dostu nanokompozitlerin geliştirilebilmesi için nano-dolguların özelliklerinin ve etkilerinin bilinmesi önemlidir. $\mathrm{Bu}$ bağlamda üç farklı 
nano-katk1 maddesi ile hazırlanan PLLA nanokompozitlerin yapısal ve ısıl özellikleri SEM, XRD ve TGA yöntemleri ile incelenecek ve sonuçlar literatürdeki benzer çalışmalar ile karşılaştırılacaktır.

\section{Materyal ve Metot}

Materyal: Çalışmada kullanılan 3,6-dimetil1,4-dioksan-2,5-dion (L-laktit), pentaeritritol $\left(\mathrm{C}_{5} \mathrm{H}_{12} \mathrm{O}_{4}\right)$, kalay-2-etil heksanoat $\left(\mathrm{Sn}(\mathrm{Oct})_{2}\right)$, çok duvarlı karbon nanotüp (çap 10-40 nm, uzunluk $0,5-1,5 \mathrm{~mm}, \quad>95 \%$ Karbon), hekzadesil trimetil amonyum bromür (HTAB), asetik asit, metilen mavisi, benzen, etanol, kloroform, sodyum klorit, potasyum hidroksit ve sülfürik asit Sigma-Aldrich'ten temin edilmiş ve herhangi bir işlem uygulanmadan olduğu gibi kullanılmıştır.

Organo-montmorillonit hazırlamak için ilk önce Tokat/Reşadiye bölgesinden alınan bentonit sedimentasyon işlemi ile saflaştırılmıştır. $\mathrm{Bu}$ işlem için, 50 gram ham kilin üzerine 2,5 litre saflaştırılmış su eklenmiş ve çözününceye dek karıştırılmıştır. Karışım, oda sıcaklığında üç gün bekletildikten sonra kabın orta bölgesi pipetle dikkatlice çekilerek başka bir kaba aktarılmıştır. Böylece dipte kalan çökelti uzaklaştırılmıştır. Diğer kaba aktarılan kil çözeltisine tekrar saf su eklenmiş ve karıştırılmıştır. $\mathrm{Bu}$ işlem dipte çökelti kalmayana dek defalarca tekrarlanmıştır. En son çöktürme işlemi de yapıldıktan sonra kil çözeltisi 6000 rpm'de 20 dk santrifüjlenmiş ve elde edilen açık sarı renkli montmorillonit (MMT), $90{ }^{\circ} \mathrm{C}$ 'de etüvde kurutulmuştur. MMT öğütüldükten sonra katyon değişim kapasitesi (KDK) belirlenmiştir. KDK'nin belirlenmesi için metilen mavisi adsorpsiyonu yöntemi kullanılmıştır. KDK değeri 100 gram kil için 110 mmol olarak belirlenmiştir. Daha sonra MMT’ten 20 gram alınarak üzerine 1 litre ve $2 \mathrm{M} \mathrm{NaCl} \mathrm{çözeltisi}$ eklenmiştir. Karışım oda sıcaklığında manyetik karıştırıcı kullanılarak 500 rpm'de 24 saat karıştırılmıştır. Vakum fỉltrasyonla süzüldükten sonra defalarca saflaştırılmış su ile y1kanan Na-MMT, etüvde kurutulmuş ve ögütülmüştür. Na-MMT'ten, OMMT hazırlamak için katyon değişim kapasitesinin (110mmol/100 g kil) 1,5 katı kadar HTAB içeren çözeltide $60 \quad{ }^{\circ} \mathrm{C}$ 'de 24 saat karıştırılmıştır. Elde edilen organomontmorillonit saf su ile defalarca yıkanmıştır (Karakehya and Bilgiç, 2014). Nanokristalin selüloz üretiminde ise Antalya/Beymelek bölgesindeki seralardan alınan domates bitkisinin sapları kurutulmuş ve selüloz izolasyonu için bir dizi işleme tabi tutulmuştur. Domates bitkisi sapları $90{ }^{\circ} \mathrm{C}$ 'de etüvde kurutulduktan sonra, bir Retsch (SK 100) rotorlu öğütücü ile toz haline getirilmiştir. Eleme işleminden sonra tanecik boyutu $90 \mu \mathrm{m}$ 'nin altındaki kısım $90{ }^{\circ} \mathrm{C}$ 'de 6 saat daha kurutulduktan sonra selüloz ekstraksiyon çalışmalarında kullanılmak üzere oda sıcaklığında ve cam şişelerde saklanmıştır. Selüloz ekstraksiyonu için 25 gram domates bitkisi sap1 $450 \quad \mathrm{ml}$ benzen/etanol (hacimce 2:1 oranında) karışımında oda sıcaklığında 20 saat karıştırılmıştır. Vakum filtrasyonla süzüldükten sonra defalarca saflaştırılmış su ile yıkanmış ve $55{ }^{\circ} \mathrm{C}$ 'de etüvde kurutulmuştur. Sonrasında ağartma işlemi için ağırlıkça \% 1,4 sodyum klorit içeren ve asetik asit kullanılarak pH'1 4'e ayarlanan $1000 \mathrm{ml}$ saf su çözeltisinde $70{ }^{\circ} \mathrm{C}$ 'de 4 saat karıştırılmıştır. Tekrar vakum filtrasyon ve yıkama işlemi uygulanmıştır. Ağartma işlemi 4 kez tekrarlanmıştır. Açık sarı renkli tortu, potasyum hidroksit çözeltisinde $(600 \mathrm{ml}$ ve ağırlıkça $\% \quad 5 \quad \mathrm{KOH}) \quad 90{ }^{\circ} \mathrm{C}$ 'de 4 saat karıştırılmıştır. Elde edilen selüloz santrifüjle çözeltiden uzaklaştırılmış ve defalarca saf su ile yıkanmıştır. Daha sonra selüloz 
dondurularak kurutulmuştur (Christ ALPHA 24 LD plus freeze dryer). Nanokristalin selüloz üretimi için ağırlıkça \% 60 sülfürik asit içeren $90 \mathrm{ml}$ sülfürik asit çözeltisine 6 gram selüloz konulmuştur. Karışım çalkalamalı su banyosunda (Nüve ST 30) 40 ${ }^{\circ} \mathrm{C}$ 'de ve $110 \mathrm{rpm}$ çalkalama hızında 40 dakika bekletilmiştir. $\mathrm{Bu}$ süre sonunda karışımın hacimce on katı soğuk su eklenerek hidroliz durdurulmuştur. Elde edilen süspansiyon $10{ }^{\circ} \mathrm{C}$ 'de ve $7000 \mathrm{rpm}$ 'de $15 \mathrm{dk}$ santrifüjlenmiştir (Thermo SL $8 \mathrm{R}$ ). Kalıntıları uzaklaştırmak için nanokristalin selüloz (NCC) saf suya karşı diyaliz edilmiştir. Daha sonra süspansiyon buz banyosunda 30 dakika soniklenmiş, ardından dondurularak kurutulmuştur (Karakehya and Bilgiç, 2019). Hazırlanan NCC daha sonraki nanokompozit hazırlama çalışmalarında kullanılmak üzere cam şişelerde depolanmıştır.

PLA nanokompozitlerin sentezi: 20 gram L-laktit dimeri, 3 boyunlu 100 mL'lik cam balona konulduktan sonra üzerine molce $\% 0,05$ pentaeritritol ve yine molce \%0,3 $\mathrm{Sn}(\mathrm{Oct})_{2}$ eklenmiştir. Cam balondan sürekli azot gazı geçirilerek balonun içindeki hava uzaklaştırılmıştır. Üç farklı nano-katkı malzemesi kompozit üretiminde kullanılmıştır. Bunlar organo-montmorillonit (OMMT), nanokristalin selüloz (NCC) ve çok duvarlı karbon nanotüptür (CNT). Bu güçlendirici katk1 malzemeleri, L-laktik miktarının ağırlıkça \%2'si kadar eklenmiştir. Tüm kimyasallar ve güçlendirici dolgu maddesi eklendikten sonra balon, vakum uygulanarak kapatılmıştır. Bu balon ısıtıcılı manyetik karıştırıcı üzerindeki ve $90{ }^{\circ} \mathrm{C}$ 'deki yağ banyosuna yerleştirilmiştir. Bu sıcaklıkta 20 dakika sürekli karıştırıldıktan sonra sıcaklık $145^{\circ} \mathrm{C}$ 'ye yükseltilmiş ve bu şekilde 12 saat daha karıştırılmıştır. Elde edilen nanokompozit malzeme kloroform yardımı ile çözülerek balondan çıkarılmış ve etüvde kurutulmuştur. Üretilen nanokompozitler içeriklerine göre kodlanmıştır. PLLA, saf poli(L-laktik asit)'in kısaltmasıdır. PLLANCC, PLLA-OMMT, PLLA-CNT kısaltmaları ise sırasıyla nanokristalin selüloz, organo-montmorillonit ve karbon nanotüp ile güçlendirilmiş nanokompozitleri ifade etmektedir. $\mathrm{Bu}$ çalışmada tüm nanokompozitler ağırlıkça \%2 oranında dolgu maddesi (NCC, OMMT veya CNT) içermektedirler.

Karakterizasyon: XRD ve TGA analizleri için saf PLLA ve PLLA nanokompozitler, sıv1 azot bağlantılı bir bilyeli öğütücü (Retsch CryoMill) kullanılarak toz haline getirilmiştir. Eleme işleminden sonra, 150$200 \mu \mathrm{m}$ arasındaki fraksiyon TGA analizi için, $60 \mu$ m'nin altındaki fraksiyon XRD analizi için kullanılmıştır. Numunelerin XRD desenlerinin belirlenmesi için Rigaku Ultima-IV difraktometre cihazı ile $\mathrm{CuK} \alpha$ radyasyonu (40kV/30mA) kullanılmıştır. Ölçümler $0.02^{\circ} \mathrm{dk}^{-1}$ tarama hızında $5^{\circ}$ ile $50^{\circ}$ (20) arasında kaydedilmiştir. Bu çalışmada TGA, azot atmosferi altında $30^{\circ} \mathrm{C}$ ila $600{ }^{\circ} \mathrm{C}$ arasında dakikada $10{ }^{\circ} \mathrm{C}$ tarama hızında bir Perkin Elmer Pyris 1 termogravimetrik analiz cihazı kullanılarak gerçekleştirilmiştir. NCC'nin geçirimli elektron mikroskobu (TEM) görüntüsü, JEOL 1220 JEM cihazında 20000 büyütmede kaydedilmiştir. CNT, PLLA ve PLLA nanokompozitlerin SEM görüntüleri Hitachi Regulus 8230 cihazında, OMMT'in SEM görüntüsü ise JEOL JSM 5600 cihazında kaydedilmiştir. $\mathrm{Bu}$ çalışmada kullanılan nano-dolgu maddelerinin elektron mikroskobu görüntüleri Şekil 1'de verilmiştir. Şekil 1 A, selülozun nano boyuta başarılı bir şekilde indirildiğini göstermektedir. Şekil $1 \mathrm{~B}, \mathrm{CNT}$ için üretici firmanın verdiği bilgileri doğrulamaktadır. Şekil 1 C'den OMMT’nin, 
üst üste istiflenmiş pürüzsüz tabakalar şeklinde bir yapı sergilediği görülmektedir.
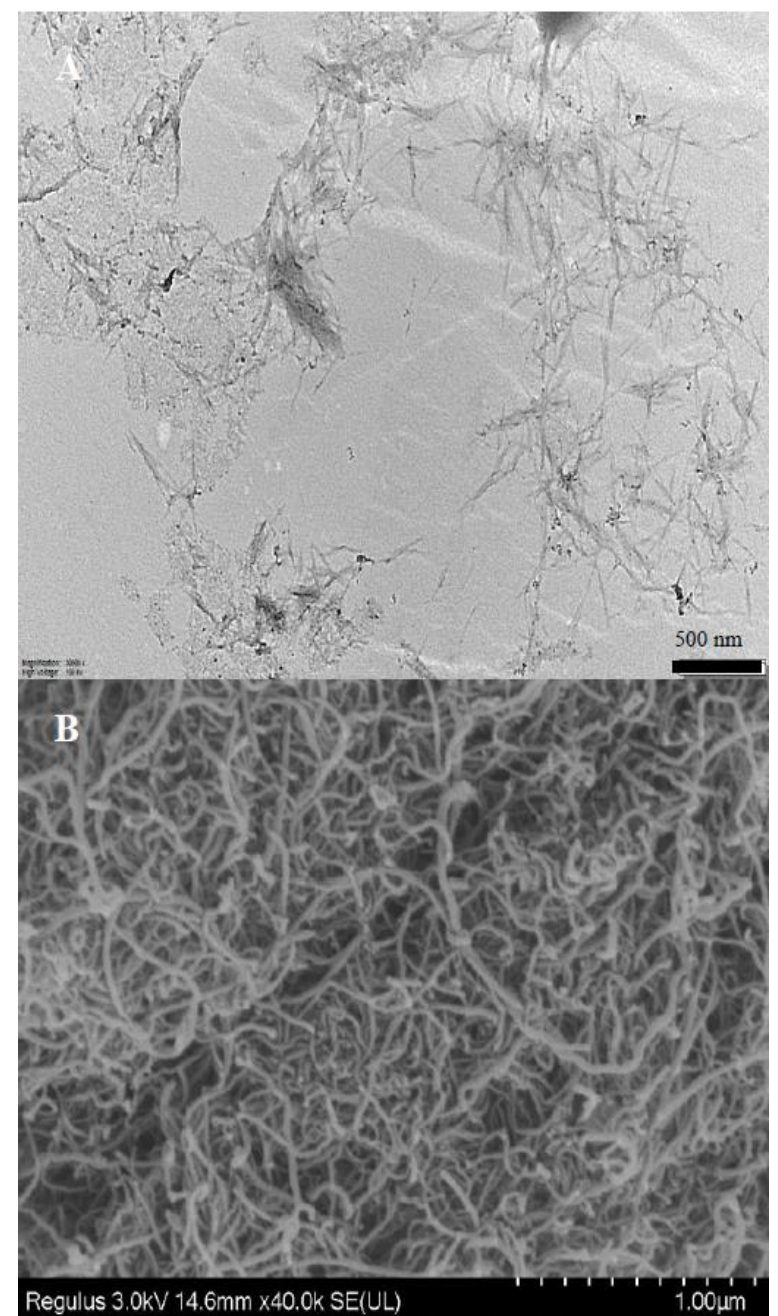

$1.00 \mu \mathrm{m}$

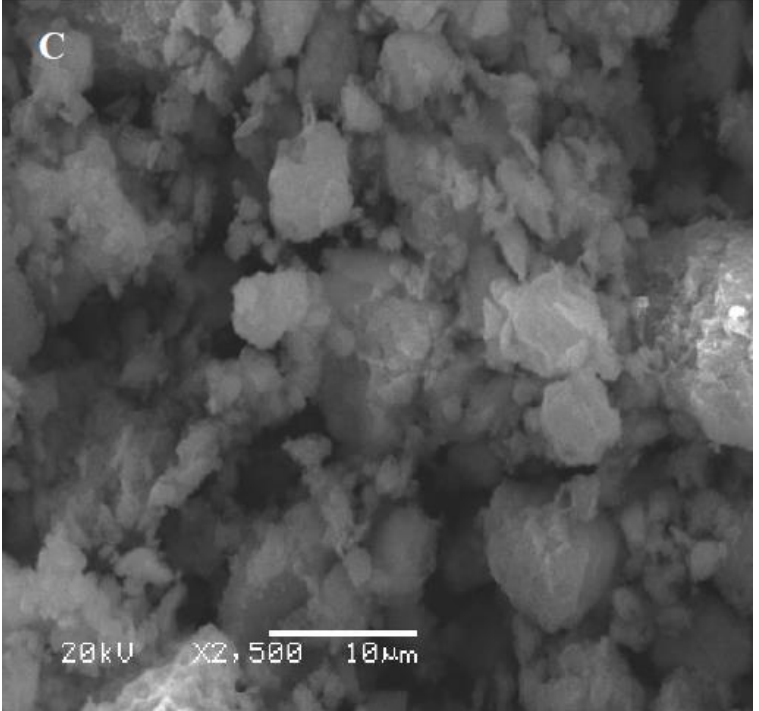

Şekil 1. A, NCC'nin TEM görüntüsü. B, CNT'nin SEM görüntüsü. C, OMMT'nin SEM görüntüsü

\section{Bulgular}

Nano-katk1 maddelerinin PLLA içindeki dağılımı incelemek için yapılan XRD analizinden elde edilen kırınım desenleri Şekil 2'de verilmiştir.

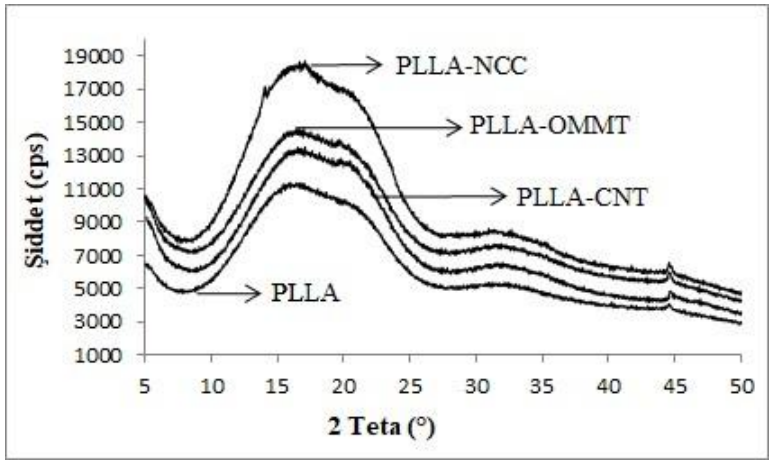

Şekil 2. PLLA ve PLLA nanokompozitlerin XRD spektrumları

Saf PLLA ve PLLA nanokompozitlerin benzer kristal yapıya sahip olduğu ve ağırlıkça \%2 oranında eklenen nanodolguların PLLA matrisinin kristal özelliklerini çok fazla değiştirmediği Şekil 2 'de görülmektedir. Tüm desenler yayvan pikler içermektedir ve kristal PLLA yapısının göstergesi olan keskin pikler gözlemlenmemiştir. Benzer sonuçlar Liu vd. (2012) tarafindan da bildirilmiştir. Numunelerin tümünde 6 ve $20^{\circ}$ 'de kısmen çakışan iki kırınım piki gözlenmektedir. PLLA'nın $16^{\circ}$ 'deki amorf polimerler için karakteristik olan geniş piki (Kaczmarek et al., 2013; Silverajah et al., 2012), bu çalışmada hazırlanan nanokompozitlerde de aynı şekilde görülmektedir. Park vd. (2015), hazırladıkları çok duvarlı karbon nanotüp/PLA nanokompozitlerde, dolgu maddesinin ağırlıça $\% 3$ oranında eklenmesinde dahi PLA'nın XRD desenlerinde önemli bir değişim gözlenmediğini bildirmişlerdir.

Isıl kararlılık polimerler için çok önemli bir parametredir. Hem polimerlere uygulanan 
işlemlerde hem de polimerin kullanıldığ çevre koşullarında ulaşılabilecek maksimum sicaklığı belirler. PLLA ve PLLA nanokompozitlerin azot atmosferinde 1s1 bozunma davranışlarını incelemek için yapılan TG analizlerden elde edilen sıcaklığa karşı ağırlık değişimi eğrileri Şekil 3’te verilmiştir. Nano-katkıların PLLA'nın 1sıl bozunma özelliklerini oldukça etkilediği görülmektedir. Tüm nanokompozitlerin TGA eğrileri saf PLLA'ya göre sola kaymıştır. Bu da nanokompozitlerde isıl bozunmanın daha düşük sıcaklıklarda gerçekleştiğini göstermektedir. PLLA ve PLLA nanokompozitlerin sıcaklığa karşı ağırlık kaybı hızı (DTG) Şekil 4'te verilmiştir. Bu grafik, maksimum ağırlık kaybının oluştuğu sıcaklıkları gözlemlemeyi kolaylaştırır. Daha önce yapılan birçok çalışmadan PLA'nın bozunmaya yaklaşık $320{ }^{\circ} \mathrm{C}$ 'de başladığı ve bozunmanın yaklaşık $400 \quad{ }^{\circ} \mathrm{C}$ 'de tamamlandığı, ayrıca bozunmanın tek adımda gerçekleştiği görülmektedir (Kang et al., 2018; Zhang et al., 2015).

Şekil 4 incelendiğinde Saf PLLA'nın bozunmaya yaklaşık $250{ }^{\circ} \mathrm{C}$ 'de başladığı ve bozunmanın yaklaşık $300 \quad{ }^{\circ} \mathrm{C}$ 'de tamamlandığı görülmektedir. Yıldız şekilli PLLA'nın bozunma sicaklık aralığı azalan kristallik nedeniyle düz zincirli PLA'ya göre çok daha düşüktür (Srisa-ard and Baimark, 2010). Tüm numunelerin $100{ }^{\circ} \mathrm{C}$ civarında gösterdiği ağırlık kaybı fiziksel bağlı suyun uzaklaşmasındandır.

Şekil 4'te görüldüğü üzere PLLA, PLLANCC ve PLLA-CNT'nin bozunma süreci iki basamakta gerçekleşmektedir ve bu numunelerin bozunma eğrileri birbirine çok benzemektedir. Arvanitoyannis ve arkadaşları, bu iki basamaklı bozunmayı, PLLA zincir uçlarında bulunan $-\mathrm{OH}$ gruplarının tetiklediği postkondenzasyonla/çapraz bağlanmayla açıklamışlardır (Arvanitoyannis et al., 1995). Post-kondenzasyonda, inert atmosferde isının etkisiyle polimer içindeki kirlilikler uzaklaşır ve zincir uzunluğu artar. PLA için benzer bir DTG grafiği Kaewpirom ve Worrarat tarafından sunulmuştur (Kaewpirom and Worrarat 2014). PLLA'nın bozunmasındaki temel mekanizma ester gruplarının hidrolizi ile bağlantılıdır (Ma et al., 2014). En keskin ve en kuvvetli DTG piklerini PLLA-OMMT sergilemiştir, bozunma basamaklarının sıcaklığı açıkça okunabilmektedir $\left(270{ }^{\circ} \mathrm{C}\right.$ ve $\left.273^{\circ} \mathrm{C}\right)$. PLLA-OMMT'nin TGA eğrisi saf PLLA'ya göre sola kaymıştır. Yüksek sıcaklıklarda killerin PLA deformasyonunu hızlandığı başka araştırmacılar tarafindan da gözlemlenmiştir (Chang et al., 2002). En düşük isıl özellikler PLLA-NCC'de gözlenmiştir. Nanokristalin selüloz çok fazla $-\mathrm{OH}$ grubuna sahip olduğundan polimerizasyon esnasinda PLLA'nın dallanmasını arttırarak zincir uzunluklarını kısaltmış olabilir. Böylece 1sıl kararlılığ1 daha düşük bir ürün elde edilmiş olur. PLLACNT'nin 1sıl kararlılığının saf PLLA'dan daha düşük olmasının nedenlerinden biri CNT'nin yüksek isıl iletkenliği olabilir. CNT, kolayca isınarak yüksek sıcaklığa ulaştığından çevresindeki moleküllerin erken bozunmasına yol açabileceği düşünülmektedir (Ahmad et al., 2020).

Ayrıca belirtmek gerekir ki bu çalışmada nano-katkı maddeleri polimere ağırlıça \%2 oranında katılmıştır. NCC, OMMT ve CNT'nin PLLA'nın 1sıl özellikleri üzerindeki etkisini daha iyi kavrayabilmek için ileriki çalışmalarda daha yüksek veya daha düşük nano-katkı maddesi oranlarının çalışılması daha kapsamlı bir değerlendirme yapma şansı tanıyacaktır. 


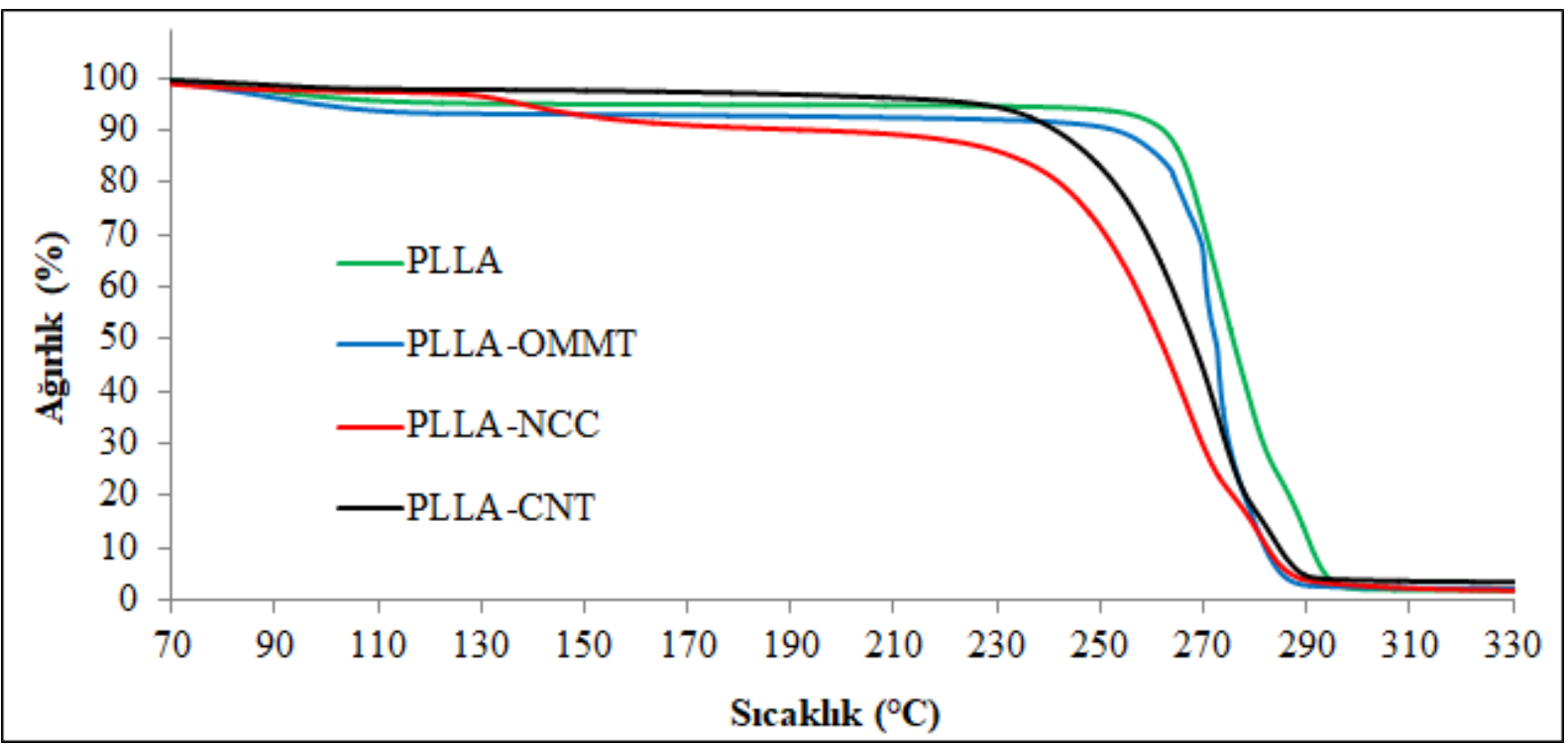

Şekil 3. PLLA ve PLLA nanokompozitlerin TGA eğrileri

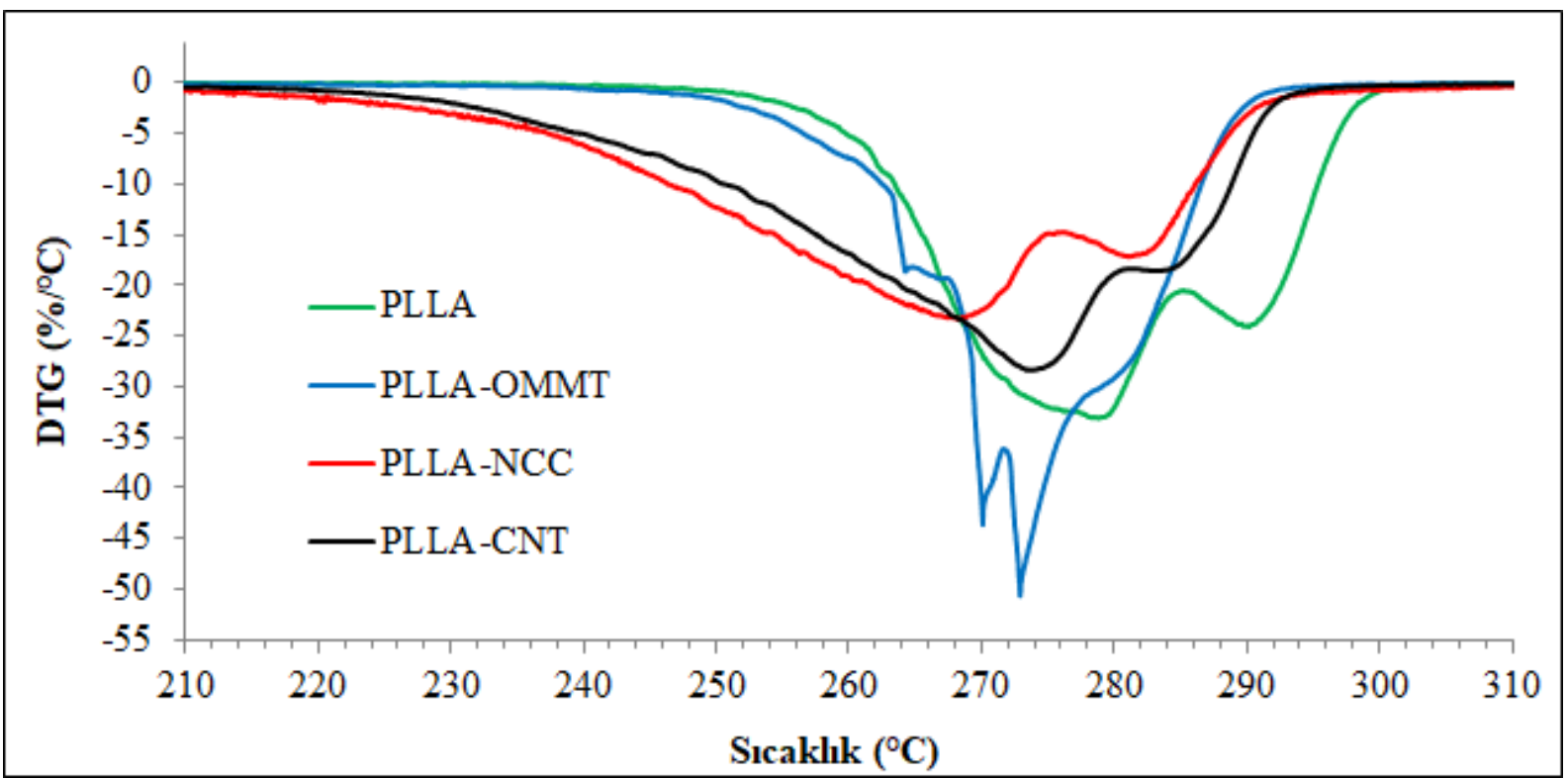

Şekil 4. PLLA ve PLLA nanokompozitlerin DTG eğrileri 


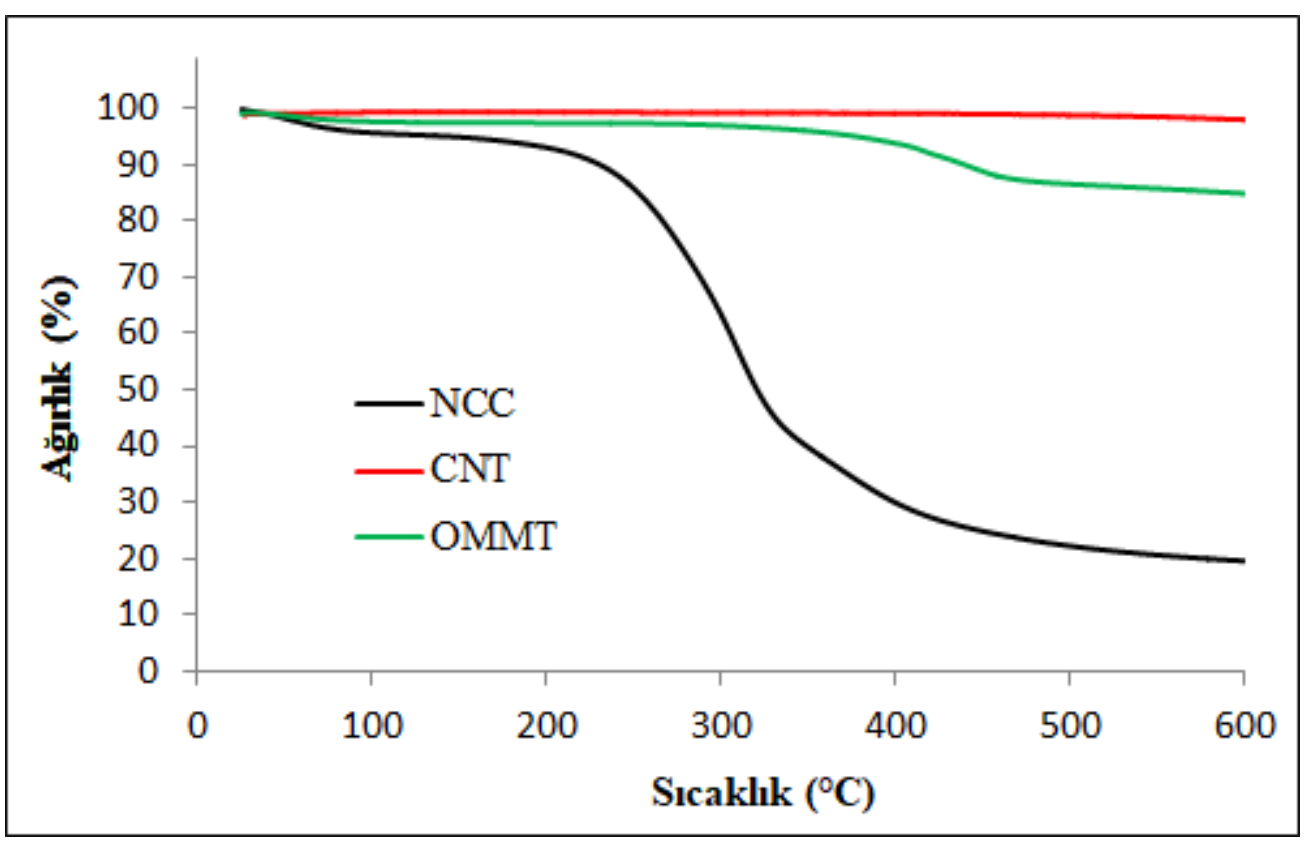

Şekil 5. OMMT, CNT ve NCC'nin TGA eğrileri

Nanokompozit hazırlanmasında kullanılan nano-katkıların TGA eğrileri Şekil 5'te verilmiştir. CNT'nin 1sıl kararlılı̆̆ çok yüksektir ve $500{ }^{\circ} \mathrm{C}$ 'de sergilediği ağırlık kaybı \%1 civarındadır. Isıl bozunmaya karşı direnci en düşük olan nano-katkı maddesi ise NCC'dir. TGA ölçümlerine göre $500{ }^{\circ} \mathrm{C}$ 'ye gelindiğinde $\mathrm{NCC}$, başlangıçtaki ağırlığının sadece \%22'sini koruyabilmiştir. Şekil 3 incelendiğinde 1 s1l direnci en düşük nanokompozit örneğinin de PLLA-NCC olduğu görülmektedir. OMMT'nin ağırlık kaybı daha çok tabakaları arasına yüklenen organik katyonik sürfaktandan (HTAB) kaynaklanmaktadır. OMMT'nin $500{ }^{\circ} \mathrm{C}$ 'ye kadar sergilediği ağırlık kaybı yaklaşık $\% 14$ 'tür.

Yüzde $5\left(\mathrm{~T}_{5 \%}\right)$ ve yüzde $50\left(\mathrm{~T}_{50 \%}\right)$ ağırlık kaybı ve maksimum ( $\left.\mathrm{T}_{\max }\right)$ ağırlık kaybı sıcaklıkları ve $500{ }^{\circ} \mathrm{C}$ 'deki çar miktarı $\left(\mathrm{M}_{\text {çar }}\right)$ Çizelge 1'de verilmiştir. Buradaki $\mathrm{T}_{5 \%}$ genellikle bozunmanın başladığı sıcaklık (onset) olarak kabul edilir. Çizelge 1'e göre bozunmaya en geç başlayan ve $500{ }^{\circ} \mathrm{C}$ 'deki kalıntısı (çar miktarı) en fazla olan nanokompozit PLLA-CNT'dir. Tüm nanokompozitlerin ağırlıkça \%50 bozunma sicaklığı saf PLLA'den en az $3,4^{\circ} \mathrm{C}$ (PLLAOMMT) en fazla $14,1^{\circ} \mathrm{C}$ (PLLA-NCC) daha düşüktür.

Çizelge 1. PLLA ve PLLA nanokompozitlerin ısıl kararlılığ1

$\begin{array}{lllll}\text { Numune } & \mathbf{T}_{5 \%} & \mathbf{T}_{\mathbf{5 0} \%} & \mathbf{T}_{\max } & \mathbf{M}_{\text {çar }}\end{array}$

PLLA $\quad 141,2 \quad 275,7 \quad 278,9 \quad 1,4$

\begin{tabular}{lllll}
\hline $\begin{array}{l}\text { PLLA- } \\
\text { OMMT }\end{array}$ & 97,7 & 272,3 & 272,9 & 1,4 \\
\hline $\begin{array}{l}\text { PLLA- } \\
\text { NCC }\end{array}$ & 137,7 & 261,6 & 268,3 & 1,1 \\
\hline $\begin{array}{l}\text { PLLA- } \\
\text { CNT }\end{array}$ & 226,2 & 267,9 & 273,7 & 3,0 \\
\hline
\end{tabular}

$\mathrm{T}_{5 \%}, \mathrm{~T}_{50 \%}$ ve $\mathrm{T}_{\max }:{ }^{\circ} \mathrm{C}, \mathrm{M}_{\text {çar }}:$ Ağırlıkça $\%$ 

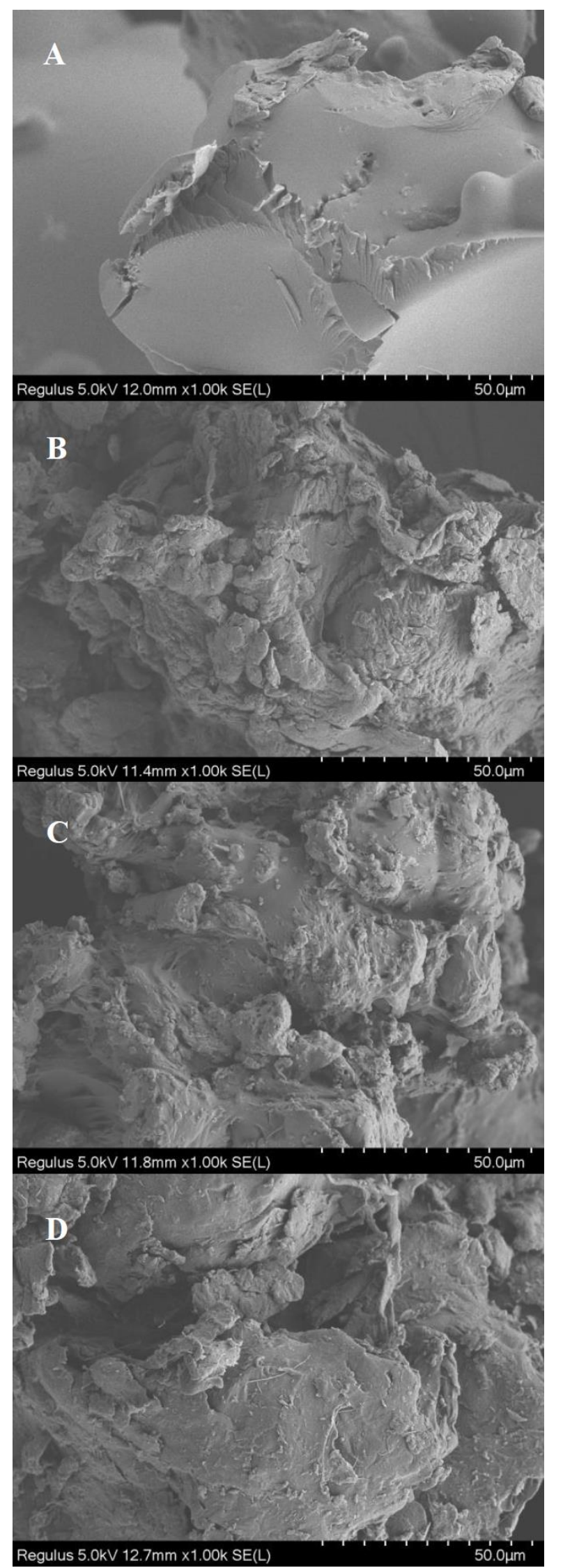

Şekil 6. Saf PLLA ve PLLA nanokompozitlerin SEM görüntüleri. A, saf PLLA; B, PLLA-OMMT; C, PLLA-NCC; D, PLLA-CNT
Saf PLLA ve PLLA nanokompozitlerinin SEM görüntüleri Şekil 6'da verilmiştir. Saf PLLA'nın SEM görüntüsünden (Şekil 6 A) pürüzsüz bir yüzey görülmektedir. Ayrıca kırma işleminden kaynaklanan çatlaklar bulunmaktadır. PLLA-OMMT'nin yüzeyi (Şekil 6 B) saf PLLA'ya göre daha engebelidir ve yer yer yumrular gözükmektedir. Şekil 6 B'ye dayanarak OMMT'nin PLLA içinde iyi bir dağılım dösterdiği söylenebilir. Eğer OMMT polimer içinde yeterince iyi bir dağılma göstermeseydi, PLLA ile OMMT arasındaki saçılma yoğunluğu farkından dolayı büyük kil kümeleşmeleri SEM görüntüsünde rahatlıkla görülebilirdi (Chang et al., 2002). PLLA-NCC ve PLLA-CNT'nin SEM görüntülerinde de benzer şekilde engebeli bir yüzey yapısı görülmektedir. Özellikle PLLACNT'nin SEM görüntüsü yakından incelendiğinde (Şekil 6 D) CNT'nin PLLA içinde çok iyi dağıldığı görülmektedir.

\section{Sonuç}

$\mathrm{Bu}$ çalışmada, polimer matris olarak kullanılan poli(L-laktik asit) (PLLA), yenilenebilir kaynaklardan elde edilen laktik asitten halka açılma polimerizasyonu ile sentezlenmiştir. Çalışmada kullanılan Sntemelli katalizör, diğer ağır metal içeren katalizörlere göre çok daha az toksiktir. PLLA sentezi esnasında nano-seviyedeki dolgu maddeleri eklenerek çeşitli nanokompozit malzemeler hazırlanmıştır. Sentezlenen saf PLLA polimerinin ve ağırlıkça \%2 dolgu maddesi içeren nanokompozitlerin yapisal ve termal özellikleri belirlenerek, saf PLLA ve kendi aralarında kıyaslanmıştır.

Saf PLLA ve nanokompozitlerin XRD analizlerinde PLLA'nın kristalliğinin eklenen nano-dolgulardan etkilenmediği 
görülmektedir. Benzer sonuçlara birçok çalışmada rastlanmaktadır (Gazzotti et al., 2017; Zhou et al., 2018). Nanokompozitlerin ve saf PLLA'nın 1s1 kararl111kları TGA ve DTG ile karakterize edilmiştir. Bu çalışmada PLLA ve PLLA nanokompozitlerin TGA termogramlarından elde edilen bozunma sıcaklıkları ve $500{ }^{\circ} \mathrm{C}$ 'deki çar miktarı verilmiştir. TGA eğrileri incelendiğinde saf PLLA'nın $250-300{ }^{\circ} \mathrm{C}$ arasinda bozunmaya uğradığı görülmektedir. Nanokompozitlerin ilk bozunma sıcaklıkları kendi içinde kıyaslandığında, PLLA-CNT için ilk bozunma sıcaklığının daha yüksek değere, PLLA-NCC ve PLLA-OMMT için daha düşük değerlere kaydığı görülmektedir. PLA'nın polimer endüstrisindeki işlem sıcaklığ $220^{\circ} C^{\prime}$ dir (Das et al., 2010). Şekil 4'de görüldüğü üzere bu çalışmada elde edilen saf PLLA ve PLLA nanokompozitlerin $220^{\circ} \mathrm{C}$ 'ye kadar bozunma hızı çok düşük seviyededir. Şekil 3'e göre en düşük ısıl kararlığı gösteren PLLA-NCC bile $220{ }^{\circ} \mathrm{C}$ 'ye kadar ağırlığının \%88'ini korumaktadır. PLLA-CNT'nin $500{ }^{\circ} \mathrm{C}$ 'deki çar miktarının saf PLLA'dan daha yüksek, PLLA-NCC'nin çar mikratının ise saf PLLA'dan daha düşük olduğu söylenebilir. $\mathrm{Bu}$ çalışmada genel olarak bakıldığında nanokompozitlerin, saf PLLA polimerinin bozunma sıcaklığından daha düşük sıcaklıklarda bozunmaya başladığı görülmüştür. PLLA için $\mathrm{T}_{5} \%, 141{ }^{\circ} \mathrm{C}$ iken nanokompozitler için bu değerler $98-226^{\circ} \mathrm{C}$ arasındadır. Örneklerin \%50'sinin bozunduğu sıcaklık olan $T_{50 \%}$ ise PLLA için $276{ }^{\circ} \mathrm{C}$ iken bu değer nanokompozitler için 267-272 ${ }^{\circ} \mathrm{C}$ arasında değişmektedir. NCC'nin polimerin bozunmasını hizlandıran etki gösterdiği görülmüştür.

Yerinde (in-situ) polimerizasyon yöntemiyle nanokompozit hazırlanması, çözeltilerin birleştirilmesi yöntemi ve eriyik harmanlama gibi kimyasallar ve ek işlemler gerektirmediğinden daha basit, ekonomik ve çevre dostu bir yöntemdir. Bununla birlikte, literatürde birçok çalışmada nano-dolgu maddesinin hazır PLA'ya çözeltilerin birleştirilmesi yöntemiyle veya eriyik harmanlama yöntemiyle katıldığında polimerin 1s1 özelliklerini geliştirdiği gözlenmiştir (Zaidi et al., 2010; Khoo et al., 2016; Zhou et al., 2018). Ancak nano-dolgu PLA sentezi esnasında katıldığında dolgu maddesinin sahip olduğu fonksiyonel gruplar sentez esnasında polimerin zincir oluşumunu etkileyerek 1sıl kararlılığını bir miktar aşağı çekmektedir. Daha sonraki çalışmalarda nano-dolgu maddelerinin PLLA'nın mekanik ve yüzey özelliklerinin üzerindeki etkisi incelenebilir. $\mathrm{Bu}$ şekilde nano-dolgu maddeleri için daha detaylı bir fayda analizi yapılabilir.

Teşekkür: $\mathrm{Bu}$ çalışma finansal olarak Eskişehir Osmangazi Üniversitesi Bilimsel Araştırma Projeleri Komisyonunca desteklenmiştir (Proje Numarasi: 201544004, 2015-555).

\section{Kaynaklar}

Ahmad, A.F., Aziz, S.A., Obaiys, S.J., Zaid, M.H.M., Matori, K.A., Samikannu, K., Aliyu, U.S., 2020. "Biodegradable Poly (lactic acid)/Poly (ethylene glycol) Reinforced Multi-Walled Carbon Nanotube Nanocomposite Fabrication, Characterization, Properties, and Applications", Polymers, 12, 427-448.

Alexandre, M., Dubois, P., 2000. "Polymerlayered silicate nanocomposites: preparation, properties and uses of a new class of materials", Materials Science and Engineering, 28, 1-63. 
Arvanitoyannis, I., Nakayama, A., Kawasaki, N., Yamamoto, N., 1995. "Novel star-shaped polylactide with glycerol using stannous octoate or tetraphenyl tin as catalyst: 1 . Synthesis, characterization and study of their biodegradability", Polymer, 36(15), 29472956.

Chang, J.H., An, Y.U., Sur, G.S., 2002. "Poly (Lactic Acid) Nanocomposites with Various Organoclays. I. Thermomechanical Properties, Morphology, and Gas Permeability", Journal of Polymer Science Part B, 41, 94-103.

Das, K., Ray, D., Banerjee, I., Bandyopadhyay, N.R., Sengupta, S., Mohanty, A.K., Misra, M., 2010. "Crystalline morphology of pla/clay nanocomposite films and its correlation with other properties", Journal of Applied Polymer Science, 118, 143-151.

Finne, A., Albertsson, A.-C., 2002. "Controlled Synthesis of Star-Shaped LLactide Polymers Using New Spirocyclic Tin Initiators", Biomacromolecules, 3, 684-690.

Gazzotti, S., Farina, H., Lesma, G., Rampazzo, R., Piergiovanni, L., Ortenzi, M.A., Silvani, $\quad$ A., 2017. "Polylactide/cellulose nanocrystals: The in situ polymerization approach to improved nanocomposites", European Polymer Journal, 94, 173-184.

Kaczmarek, H., Nowicki, M., VukovićKwiatkowska, I., Nowakowska, S., 2013. "Crosslinked blends of poly(lactic acid) and polyacrylates: AFM, DSC and XRD studies”, Journal of Polymer Research, 20, 91-103.

Kaewpirom, S., Worrarat, C., 2014. "Preparation and Properties of Pineapple Leaf Fiber Reinforced Poly(lactic acid)
Green Composites", Fibers and Polymers, $15,1469-1477$.

Kang, H., Li, Y., Gong, M., Guo, Y., Guo, Z., Fang, Q., Li, X., 2018. “An environmentally sustainable plasticizer toughened polylactide", RSC Advances, 8, 11643-11651.

Karakehya, N., Bilgiç, C., 2014. "Surface characterisation of montmorillonite/PVC nanocomposites by inverse gas chromatography", International Journal of Adhesion and Adhesives, 51, 140-147.

Karakehya, N., Bilgiç, C., 2019. "Preparation of nanocrystalline cellulose from tomato stem and commercial microcrystalline cellulose: a comparison between two starting materials", Cellulose Chemistry and Technology, 53, 993-1000.

Khoo, R.Z., Ismail, H., Chow, W.S., 2016. "Thermal and Morphological Properties of Poly (lactic acid)/Nanocellulose Nanocomposites. Procedia Chemistry", 19, 788-794.

Kim, S.H., Han, Y.-K., Ahn, K.-D., Kim, Y.H., Chang, T., 1993. "Preparation of starshaped polylactide with pentaerythritol and stannous octoate", Macromolecular Chemistry and Physics, 194, 3229-3236.

Lee, S. H., Kim, S.H., Han, Y.K., Kim, Y.H., 2001. "Synthesis and degradation of endgroup-functionalized polylactide", Journal of Polymer Science Part A: Polymer Chemistry, 39, 973- 985.

Liu, D.Y., Yuan, X.W., Bhattacharyya, D., 2012. "The effects of cellulose nanowhiskers on electrospun poly(lactic acid) nanofibres", Journal of Materials Science, 47(7), 31593165 . 
Lopes, M.S., Jardini, A.L., Filho, R.M., 2014. "Synthesis and Characterizations of Poly (Lactic Acid) by Ring-Opening Polymerization for Biomedical Applications", Chemical Engineering Transactions, 38, 331-336.

Ma, P., Jiang, L., Ye, T., Dong, W., Chen, M., 2014. "Poly melt free-radical grafting of maleic anhydride onto biodegradable poly(lactic acid) by using styrene as a comonomer", Polymers, 6(5), 1528-1543.

Pan, M., Shi, X., Li, X., Hu, H., Zhang, L., 2004. "Morphology and properties of pvc/clay nanocomposites via in situ emulsion polymerization", Journal of Applied Polymer Science, 94, 277-286.

Park, S.G., Hay, A.A., Lim J.K., 2015. "Biodegradable Poly(Lactic Acid)/Multiwalled Carbon Nanotube Nanocomposite Fabrication Using Casting And Hot Press Techniques", Archives of Metallurgy and Materials, 60(2), 1557-1559.

Pavlidou, S., Papaspyrides, C.D., 2008. “A review on polymer-layered silicate nanocomposites", Progress in Polymer Science, 33, 1119-1198.

Silverajah, V.S.G., Ibrahim, N.A., Yunus, W.M.Z.W., Hassan, H.A., Chieng, B.W., 2012. "A Comparative Study on the Mechanical, Thermal and Morphological Characterization of Poly(lactic acid)/Epoxidized Palm Oil Blend", International Journal of Molecular Sciences, 13, 5878-5898.

Srisa-ard, M., Baimark, Y., 2010. "Effects of arm number and arm length on thermal properties of linear and star-shaped poly(D,L-lactide)s", Journal of Applied Sciences, 10(17), 1937-1943.
Teng, L., Xu, X., Nie, W., Zhou, Y., Song, L., Chen, P., 2015. "Synthesis and degradability of a star-shaped polylactide based on L-lactide and xylitol", Journal of Polymer Research, 22(5), 1-7.

Thakur, V.K., Thakur, M.K., 2014. "Processing and characterization of natural cellulose fibers/thermoset polymer composites", Carbohydrate Polymers, 109, 102-117.

Zaidi, L., Kaci, M., Bruzaud, S., Bourmaud, A., Grohens, Y., 2010. "Effect of natural weather on the structure and properties of polylactide/Cloisite 30B nanocomposites", Polymer Degradation and Stability, 95, 17511758 .

Zhang, H., Huang, J., Yang, L., Chen, R., Zou, W., Lina, X., Qu, J., 2015. "Preparation, characterization and properties of PLA/TiO2 nanocomposites based on a novel vane extruder", RSC Advances, 5(6), 4639-4647.

Zhou, Y., Lei, L., Yang, B., Li, J., Ren, J., 2018. "Preparation and characterization of polylactic acid (PLA) carbon nanotube nanocomposites", Polymer Testing, 68, 3438. 